\title{
Pituitary adenylate cyclase activating peptides relax human pulmonary arteries by opening of $\mathrm{K}_{\mathrm{ATP}}$ and $\mathrm{K}_{\mathrm{Ca}}$ channels
}

Leonhard Bruch, Susann Rubel, Andrea Kästner, Klaus Gellert, Maik Gollasch, Christian Witt

\begin{abstract}
Background-Pituitary adenylate cyclase activating peptides (PACAPs) are potent endothelium independent dilators of human coronary arteries; however, their effects on human pulmonary arteries are unknown.

Methods-The vasorelaxant effects of PACAP27 on human pulmonary segmental arteries were studied and the specific potassium $\left(\mathrm{K}^{+}\right)$channel regulatory mechanisms in the vasorelaxant effects were tested by means of isometric contraction experiments.

Results-PACAP27 produced dose dependent relaxations of $10 \mu M$ rings preconstricted with prostaglandin $\mathbf{F}_{2 \alpha}\left(\mathbf{P G F}_{2 \alpha}\right)$ with half maximal relaxation $\left(\right.$ IC $\left._{50}\right)$ at 17 nM. Pretreatment of the vessels with the ATP sensitive $K^{+}\left(K_{\text {ATP }}\right)$ channel blocker glibenclamide $(1 \mu M)$ or with the $\mathrm{Ca}^{2+}$ activated $\mathrm{K}^{+}\left(\mathrm{K}_{\mathrm{Ca}}\right)$ channel blocker iberiotoxin (100 nM) inhibited the PACAP27 induced relaxation.

Conclusions-These results provide evidence that PACAPs are potent vasodilators of human pulmonary arteries and that this relaxation might be mediated by opening of $K_{\mathrm{ATP}}$ and $\mathrm{K}_{\mathrm{Ca}}$ channels.

(Thorax 1998;53:586-587)
\end{abstract}

Keywords: PACAP; potassium channel opener; $\mathrm{Ca}$ sparks; human pulmonary artery

Pituitary adenylate cyclase activating polypeptides (PACAP38 and PACAP27) induce specific effects on the cardiovascular system in rats, ${ }^{1}$ cats, ${ }^{2}$ and sheep. ${ }^{3}$ Our previous studies have shown that PACAP27 and PACAP38 are potent endothelium independent dilators of isolated human and porcine epicardial coronary arteries. ${ }^{45}$ Since the vasorelaxant effects of PACAP27 are inhibited by $\mathrm{K}^{+}$channel blockers, we have suggested that specific $\mathrm{K}^{+}$ channel regulatory mechanisms may be involved in the relaxation of human coronary arteries. $^{5}$ Since PACAP has recently been shown to stimulate L-type $\mathrm{Ca}^{2+}$ channels in smooth muscle cells of the rat tail artery, ${ }^{6}$ it might be expected that PACAP can also exhibit vasoconstrictory effects. However, no information has been reported on the effects of PACAP on human pulmonary arteries. Furthermore, the contractile behaviour of pulmonary arteries differs from other arterial vessels, and $\mathrm{K}^{+}$channels are diverse and their distribu- tion varies in different vascular beds and species.

A study was undertaken to test whether human segmental pulmonary arteries are dilated by PACAP27. Glibenclamide and iberiotoxin were used at concentrations that selectively block ATP sensitive $\left(\mathrm{K}_{\mathrm{ATP}}\right)$ and large conductance calcium activated $\mathrm{K}^{+}$channels $\left(\mathrm{K}_{\mathrm{Ca}}\right)$, respectively, in arterial smooth muscle ${ }^{7}$ to investigate the functional importance of the linkage between $\mathrm{K}_{\mathrm{ATP}}$ and $\mathrm{K}_{\mathrm{Ca}}$ channel activation and pulmonary relaxation induced by PACAP27.

\section{Methods}

Human pulmonary segmental arteries (diameter $1-3 \mathrm{~mm}$ ) were obtained from tumour free lung parts of patients who had undergone lobectomy or pulmonectomy due to peripheral lung cancer. The isometric tension of isolated vessel rings ( $4 \mathrm{~mm}$ in length) was measured isometrically as previously described. ${ }^{5}$ The pulmonary arteries were stretched stepwise to a resting tension of about $5 \mathrm{mN}$ and allowed to equilibrate for at least two hours. The cumulative concentration-response curves with PACAP27 were measured after precontraction of the rings with prostaglandin $\mathrm{F}_{2 \alpha}\left(\mathrm{PGF}_{2 \alpha}\right)(10$ $\mu \mathrm{M})$. Non-linear regression analysis was used to calculate half maximal relaxation $\left(\mathrm{IC}_{50}\right)$ values and Hill coefficients.

\section{STATISTICAL ANALYSIS}

All values are given as mean (SE). The term $n$ represents the number of vessel rings, only one vessel ring per patient was used for each concentration-response curve. ANOVA on ranks and the Wilcoxon rank sum test were used to determine significant differences between the different concentration-response curves at each point. A value of $p<0.05$ was considered statistically significant.

\section{Results}

PULMONARY RELAXATION BY PACAP27

In human pulmonary arteries PACAP27 induced dose dependent relaxations of rings preconstricted with $10 \mu \mathrm{M} \mathrm{PGF}_{20}$, with $\mathrm{IC}_{50}$ values at $17 \mathrm{nM}$ (fig 1). The Hill coefficient was 0.63 . PACAP27 induced relaxation to approximately $35 \%$ of preconstricted values at $0.1 \mu \mathrm{M}$. The effects of PACAP were completely reversible after washout (data not shown).

EFFECTS OF GLIBENCLAMIDE AND IBERIOTOXIN ON RELAXATION INDUCED BY PACAP27

To elucidate the role of $\mathrm{K}^{+}$channels in the vasorelaxant mechanism of the PACAPs, we 
Figure 1 Inhibition of the relaxant effects of $P A C A P 27$ on precontracted human pulmonary segmental arteries by glibenclamide (Glib, $1 \mu M)$, iberiotoxin (IbTx, $0.1 \mu M)$, or both substances $(G l i b+I b T x)$ ( $n=4-6$ vessel rings). ${ }^{\star} p<0.05$ for $P A C A P 27$ versus IbTx + PACAP27 and Glib $+\mathrm{IbTx}+$ PACAP27; ${ }^{\star *} p<0.05$ for PACAP27 versus Glib + $P A C A P 27 ;{ }^{\star \star \star} p<0.05$ for Glib + PACAP27 versus IbTx + PACAP27.

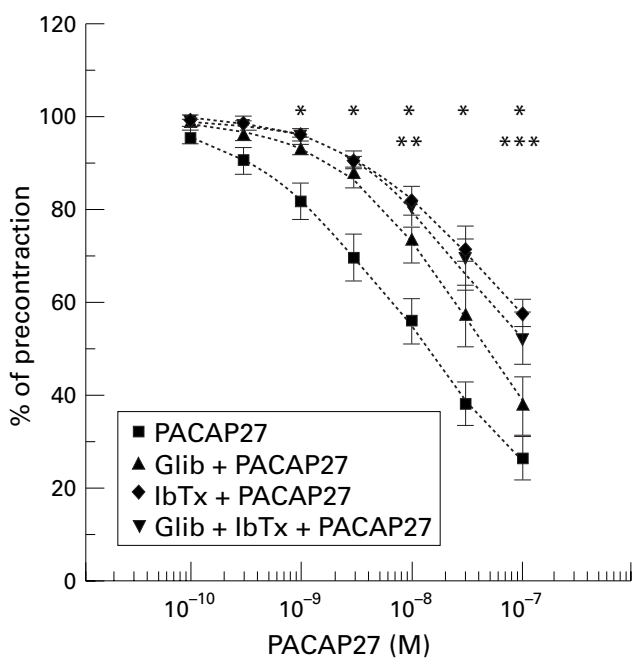

tested the effects of the ATP sensitive $\mathrm{K}^{+}$channel $\left(\mathrm{K}_{\mathrm{ATP}}\right)$ blocker glibenclamide and of the calcium activated $\mathrm{K}^{+}$channel $\left(\mathrm{K}_{\mathrm{Ca}}\right)$ blocker iberiotoxin on the PACAP27 induced relaxation of human pulmonary arteries. The concentration-response curves for relaxation induced by PACAP27 after pretreatment of $\mathrm{PGF}_{2 \alpha}$ precontracted pulmonary rings with glibenclamide $(1 \mu \mathrm{M})$, iberiotoxin $(100 \mathrm{nM})$, or both in combination are also shown in fig 1 . Both glibenclamide and iberiotoxin significantly attenuated the PACAP27 induced relaxation, but the effect of iberiotoxin was more pronounced. Application of a combination of glibenclamide $(1 \mu \mathrm{M})$ and iberiotoxin (100 $\mathrm{nM}$ ) did not result in an additive effect.

\section{Discussion}

These results provide the first evidence that PACAP27 is a potent dilator of human segmental pulmonary arteries. We have shown that glibenclamide (a specific $\mathrm{K}_{\mathrm{ATP}}$ channel blocker $^{7}$ ) and iberiotoxin (a selective $\mathrm{K}_{\mathrm{C}}$ channel blocker ${ }^{7}$ ) inhibit PACAP27 induced relaxation of human pulmonary arteries. Similar effects were observed in human coronary arteries. ${ }^{5}$ Furthermore, PACAP27 stimulated $\mathrm{K}_{\mathrm{ATP}}$ and $\mathrm{K}_{\mathrm{Ca}}$ currents in freshly isolated human coronary artery smooth muscle cells. ${ }^{5}$ We therefore propose the following cascade of events leading to relaxation of both human pulmonary and coronary arteries by PACAPs: (1) activation of $\mathrm{K}_{\mathrm{ATP}}$ and $\mathrm{K}_{\mathrm{Ca}}$ channels in smooth muscle cells, (2) increase in $\mathrm{K}^{+}$efflux, (3) membrane hyperpolarisation, (4) closure of voltage dependent $\mathrm{Ca}^{2+}$ channels, and (5) decrease of $\mathrm{Ca}^{2+}$ entry and vasorelaxation.

The mechanism by which PACAPs can stimulate $\mathrm{K}_{\mathrm{ATP}}$ and $\mathrm{K}_{\mathrm{Ca}}$ channels in smooth muscle is unknown, but might involve activation of adenylyl cyclase which has been shown in rat aortic smooth muscle cell homogenates. ${ }^{8}$ It has also been reported that activation of adenylyl cyclase and an increase in cAMP can stimulate $\mathrm{K}_{\mathrm{ATP}}$ and $\mathrm{K}_{\mathrm{Ca}}$ channels in smooth muscle cells. ${ }^{7} \mathrm{It}$ therefore seems likely that this pathway is also involved in the stimulation of these channels in human pulmonary arteries, but data concerning the coupling between increased cAMP and activation of $\mathrm{K}_{\mathrm{ATP}}$ and $\mathrm{K}_{\mathrm{Ca}}$ channels (including $\mathrm{K}_{\mathrm{Ca}}$ currents activated by Ca sparks) in human vascular smooth muscle cells are still lacking. However, it is also possible that the effects of PACAP are mediated by $\mathrm{G}$ proteins. These have been reported to stimulate potassium channels directly, in particular $\mathrm{K}_{\mathrm{Ca}}$, in vascular smooth muscle cells. ${ }^{9}$ PACAPs exert potent vasodilation in vivo in different perfusion beds, including lung. ${ }^{10}$ In the lung PACAP positive nerve fibres were immunohistochemically demonstrated around small blood vessels. These nerve fibres also store vasoactive intestinal polypeptide (VIP), as revealed by double immunostaining. ${ }^{11}$ Besides VIP, PACAP is thus a novel neurotransmitter for non-adrenergic/non-cholinergic innervation of lung blood vessels.

The results of the present study suggest that PACAPs may have a physiological significance in the pulmonary circulation since they are potent dilators of human pulmonary arteries with an $\mathrm{IC}_{50}$ in the low nanomolar range, and they stimulate $\mathrm{K}_{\mathrm{ATP}}$ and $\mathrm{K}_{\mathrm{Ca}}$ channels in smooth muscle cells to exert their vasodilatory action.

LB was supported by a grant from the Bundesministerium für Forschung und Technologie.

1 Nandha KA, Benito Orfila MA, Smith DM, et al. Action of pituitary adenylate cyclase-activating polypeptide and effects on blood pressure and receptor binding. 7 Endocrinol 1991;129:69-73.

2 Minkes RK, McMahon TJ, Hood JS, et al. Differential effects of PACAP and VIP on the pulmonary and hindquarters vascular beds of the cat. $\mathcal{F}$ Appl Physiol 1992;72:1212-7.

3 Sawangjaroen K, Dallemagne CR, Cross RB, et al. Effects of pituitary adenylate cyclase activating polypeptide and vituitary adenylate cyclase activating polypeptide and vasoactive intestinal polypeptide on the carc

4 Kästner A, Bruch L, Will Shahab L, et al. Pituitary adenylate cyclase activating peptides are endothelium-independent dilators of human and porcine coronary arteries. Agents Actions Suppl 1995;45:283-9.

5 Bruch L, Bychkov R, Kästner A, et al. Pituitary adenylate cyclase activating peptides relax human coronary arteries by activating $\mathrm{K}_{\mathrm{ATP}}$ and $\mathrm{K}_{\mathrm{Ca}}$ channels in smooth muscle cells. 7 Vasc Res 1997;34:11-8.

6 Chik CL, Li B, Ogiwara T, et al. PACAP modulates L-type $\mathrm{Ca}^{2+}$ channel currents in vascular smooth muscle cells: involvement of PKC and PKA. FASEB F 1996;10:1310-7.

7 Nelson MT, Quayle JM. Physiological roles and properties of potassium channels in arterial smooth muscle. $\mathrm{Am} 7$ Physiol 1995;268:C799-822.

8 Warren JB, Donnelly LE, Cullen S, et al. Pituitary adenylate cyclase-activating polypeptide: a novel, long-lasting, endothelium-independent vasorelaxant. Eur f Pharmacol 1991;197:131-4.

9 Scornik FS, Codina J, Birnbaumer L, et al. Modulation of coronary smooth muscle KCa channels by Gs alpha independent of phosphorylation by protein kinase A. Am $\mathcal{F}$ Physiol 1993;265:H1460-5.

10 Cheng DY, McMahon TJ, Dewitt BJ, et al. Comparison of responses to pituitary adenylate cyclase activating peptides 38 and 27 in the pulmonary vascular bed of the cat. Eur $\mathcal{F}$ Pharmacol 1993;243:79-82.

11 Uddman R, Luts A, Arimura A, et al. Pituitary adenylate cyclase-activating peptide (PACAP), a new vasoactive intestinal peptide (VIP)-like peptide in the respiratory tract. Cell Tissue Res 1991;265:197-201. 